\title{
Development of silicotic lesions in the lungs of rats pre-exposed to coal fly ash
}

\author{
J L KAW, A K KHANNA \\ From the Industrial Toxicology Research Centre, Mahatma Gandhi Marg, Lucknow 226001 , India
}

ABSTRACT The development of silicotic lesions was studied in the lungs of rats pre-exposed to a pulmonary load of coal fly ash. Exposure to quartz alone increased the wet weight, dry weight, and collagen content of the lungs. These changes were associated with an increase in the activity of lactate dehydrogenase, total proteins, and the cellularity of bronchoalveolar lavage. When the lungs of rats were pre-exposed to coal fly ash for 60 days and then exposed to quartz dust for periods similar to those used for exposure to quartz alone, the development of silicotic lesions and the laying down of collagen fibres was retarded, as judged by histopathological examination and biochemical analysis of the tissues for hydroxyproline contents. These changes in the lung tissue were associated with a significant reduction in the level of lactate dehydrogenase enzyme activity, total cell counts, and protein contents of the bronchoalveolar lavage derived from rats exposed to quartz.

Fly ash is a common environmental pollutant where coal is burnt in thermal power stations to generate electricity.' Health hazards due to its inhalation have been attributed to constituents such as trace elements, carcinogenic and potentially carcinogenic compounds, and the size of the particulates small enough to escape the dust clearing mechanism of the electrostatic precipitator. ${ }^{2-9}$

An earlier investigation showed that small doses of fly ash are readily phagocytosed by alveolar macrophages, retained in the lungs for long periods, and do not elicit a pronounced fibrotic reaction in the lungs. In the present investigation studies were carried out to determine whether a dose of fly ash, large enough to be retained in the lungs over long periods, can modify the pulmonary response to a known fibrogenic dust. The studies merit investigation since exposure to fly ash and dusts rich in free silica may occur in and around industrial settings, particularly in developing countries-among workers handling cement and sand in road and building construction, for example.

\section{Materials and methods}

PREPARATION OF FLY ASH DUST SAMPLES

Fly ash was obtained from the electrostatic precipitator of a thermal power station in India. It was passed through a 400 mesh sieve to remove coarse particles and then briefly suspended in a volume of distilled water. The supernatant containing fine parti-

Accepted 26 January 1987 cles of fly ash in suspension was siphoned off carefully, centrifuged at $800 \mathrm{~g}$ for 10 minutes, and the sediment dried at $100^{\circ} \mathrm{C}$. The fly ash particles thus obtained contained more than $90 \%$ of the particles less than $5 \mu \mathrm{m}$ in diameter.

\section{ANIMALS}

Female albino rats (body wt $150-175 \mathrm{~g}$ ), of the Industrial Toxicology Research Centre rat colony, reared under normal conditions of husbandry and fed freely on pellet diet supplied by Hindustan Lever and water, were used.

EXPERIMENTAL PROTOCOL

The rats were randomly divided into two groups, 1 and 2. The 40 rats in group 1 were inoculated intratracheally with $12.5 \mathrm{mg}$ of coal fly ash, suspended in $1 \mathrm{ml}$ physiological saline. The 35 rats in group 2 were inoculated with $1 \mathrm{ml}$ physiological saline. After a lapse of 60 days, a batch from each group was killed and the remaining rats of both groups were divided into two subgroups. The 17 rats of the first subgroup in group 1 were inoculated intratracheally with $10 \mathrm{mg}$ of quartz dust suspended in $1 \mathrm{ml}$ physiological saline and the 16 rats in the second subgroup of group 1 were inoculated with $1 \mathrm{ml}$ physiological saline. The rats in group 2 were also divided into two subgroups. The 15 rats of the first subgroup were inoculated with $10 \mathrm{mg}$ quartz dust intratracheally suspended in $1 \mathrm{ml}$ of physiological saline and the 14 rats of the second subgroup with $1 \mathrm{ml}$ of physiological saline. The details of the experimental protocol are shown diagramatically opposite. 

Group 1 Inoculated $12.5 \mathrm{mg} 60$ days (a) Inoculated $10 \mathrm{mg}$ fly ash in $1 \mathrm{ml}$ NSS quartz in $1 \mathrm{ml} \mathrm{NSS}$
Group 2 Inoculated $1 \mathrm{ml}$ NSS 60 days (b) Inoculated $10 \mathrm{mg}$
(c) Inoculated $10 \mathrm{mg}$
(d) Inoculated $1 \mathrm{ml}$ NSS

(Rats from subgroups $(a),(b),(c)$, and $(d)$, were killed 30,60 , and 90 days after intratracheal inoculation of quartz dust for evaluation.)

\section{HISTOLOGICAL METHODS}

Thirty, 60, and 90 days after intratracheal inoculation of quartz dust the rats were killed and the lungs and trachea removed and dissected free of the heart and mediastinal structures. The wet weight of the lungs and trachea was recorded, and subsequently the lungs were gently distended with a solution of $10 \%$ formolsaline $(V / V)$ injected through the trachea, which was tied at the site of the origin of the first bronchus. The trachea was then removed and its weight subtracted from the weight of the lungs and trachea to obtain the net weight subtracted from the weight of the lungs and trachea to obtain the net wet weight of lungs. The lungs were next put in $10 \%$ formol-saline with the mediastinal lymph nodes that were separately excised. After preliminary fixation, blocks of tissues were selected along the long axes of lungs and lymph nodes. The tissues were embedded in paraffin and multiple sections of $5 \mu \mathrm{m}$ thickness were cut and stained with haematoxylin and eosin and silver impregnated for reticulin. ${ }^{10}$

\section{COLLAGEN ANALYSIS}

All the lung tissue, except the portion used for histopathological studies, was dried at $110^{\circ} \mathrm{C}$. Tissue shavings and the paraffin embedded block were then added to it and the whole was treated thrice with xylene at $37^{\circ} \mathrm{C}$. The mixture was again dried until a constant weight was reached. This represented the total dry weight of lungs minus a few sections of $5 \mu \mathrm{m}$ thickness. A sample of the dried ground lung tissue was hydrolysed in $6 \mathrm{~N} \mathrm{HCl}$ in a sealed tube and hydrolysed for 16 hours at $100^{\circ} \mathrm{C}$ in a hot air oven. The hydrolysate was neutralised with the theoretical amount of $\mathrm{NaOH}$ and diluted as desired for analysis. Hydroxyproline was estimated by the method of Stegemann. " Collagen contents were determined by multiplying the hydroxyproline value by $7 \cdot 46$.

\section{COLLECTION AND ANALYSIS OF}

\section{BRONCHOALVEOLAR LAVAGE}

Bronchoalveolar lavage was collected at necropsy from rats killed at 30,60 , and 90 days after the inoculation of quartz dust. Fifteen $\mathrm{ml}$ of physiological saline were injected into the lungs through the trachea in three aliquots of $5 \mathrm{ml}$. At each injection the saline was withdrawn and reinjected thrice. Aliquots of lavage collected from the same rat were pooled in precooled tubes and centrifuged. The supernatant was used for the assay of lactate dehydrogenase ${ }^{12}$ and protein contents. ${ }^{13}$ In the sediment the number of cells were counted in a cell counter after resuspension in physiological saline.

\section{Results}

Microscopic examination of the lungs exposed to fly ash alone showed a macrophage response in the alveolar lumen. The dust was phagocytosed by macrophages. The alveolar walls showed moderate thickening due to a mononuclear cellular infiltration and the proliferation of reticulin fibres. The dust was transported to the mediastinal lymph nodes, where it was principally located in the cortical and medullary sinuses.

Exposure to quartz dust resulted in an outpouring of macrophages into the alveolar lumen, which accumulated in places and gave rise to typical granulomas. The granulomas were small and discrete at $\mathbf{3 0}$ days after exposure and increased in size subsequently. The lesions developed chiefly in the alveoli budding off from respiratory bronchioles and alveolar ducts, situated in the vicinity of small blood vessels and air ways (fig 1). The substance of the nodules was composed of a reticulin framework at 30 days after exposure. At subsequent intervals collagen fibres were seen to be distributed among the reticulin fibres. Typical silicotic nodules developed in the mediastinal lymph nodes that replaced the lymphoid elements to varying degrees (fig 2).

In rats exposed to quartz dust after an initial load of fly ash the silicotic lesions were less well developed and the histological picture of fly ash lung predominated over that due to quartz exposure. Typically, the alveolar macrophages were loaded with fly ash particles, which eclipsed the presence of quartz particulates in the haematoxylin-eosin stained sections (fig 3). The reaction at 60 days after exposure to quartz showed the presence of small nodules at the site of the bifurcation of the distal airways (fig 4). In the mediastinal lymph nodes silicotic lesions containing fly ash particles developed and the remnants of lymphoid elements seemed to be more than those observed in silicotic rats not pre-exposed to fly ash (fig 5).

The wet weight of lungs increased progressively from 30 days to 90 days after inoculation with quartz dust (table 1). This increase was highly significant at 60 and 90 days after exposure $(p<0.01)$. Rats inoculated with quartz dust after pre-exposure to fly ash also registered a significant increase in the wet weight of the lungs. A comparison of the wet weight of the lungs between the rats exposed to quartz dust alone or after pre-exposure to fly ash showed that in the lungs pre- 
Fig 1 Section of lung of rat killed 60 days after intratracheal inoculation of quartz. (Rat had been similarly inoculated 60 days earlier with $1 \mathrm{ml}$ saline) showing highly cellular silicotic granulomas in pulmonary parenchyma. (Haematoxylin and eosin $\times 150$.)

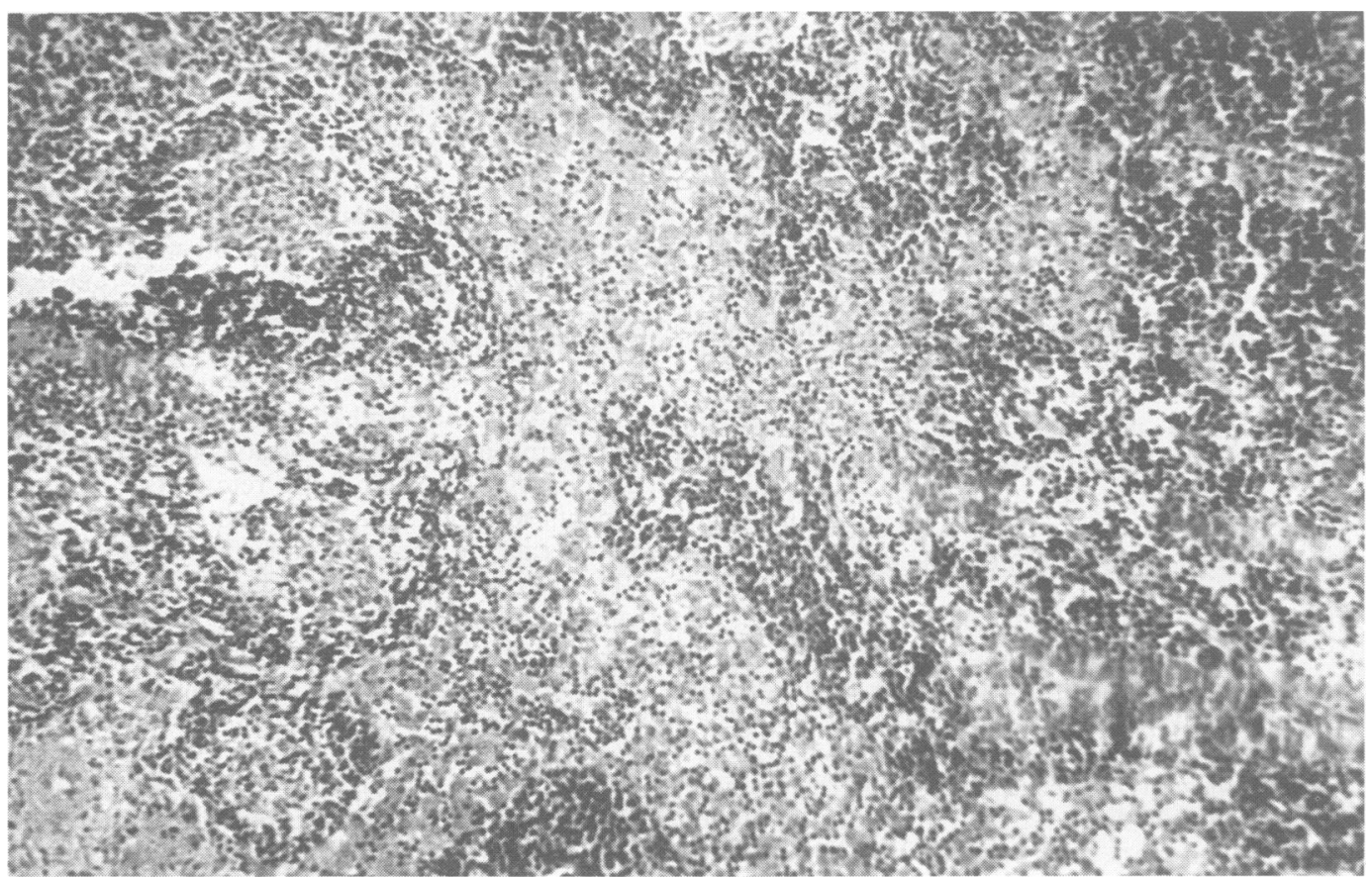

Fig 2 Section of mediastinal lymph node of rat killed 30 days after intratracheal inoculation of quartz. (Rat had been similarly inoculated 60 days earlier with $1 \mathrm{ml}$ saline.) Lymphoid elements of tissue have to a large extent been replaced by cells comprising a silicotic fibrotic reaction. (Haematoxylin and eosin $\times 60$.) 


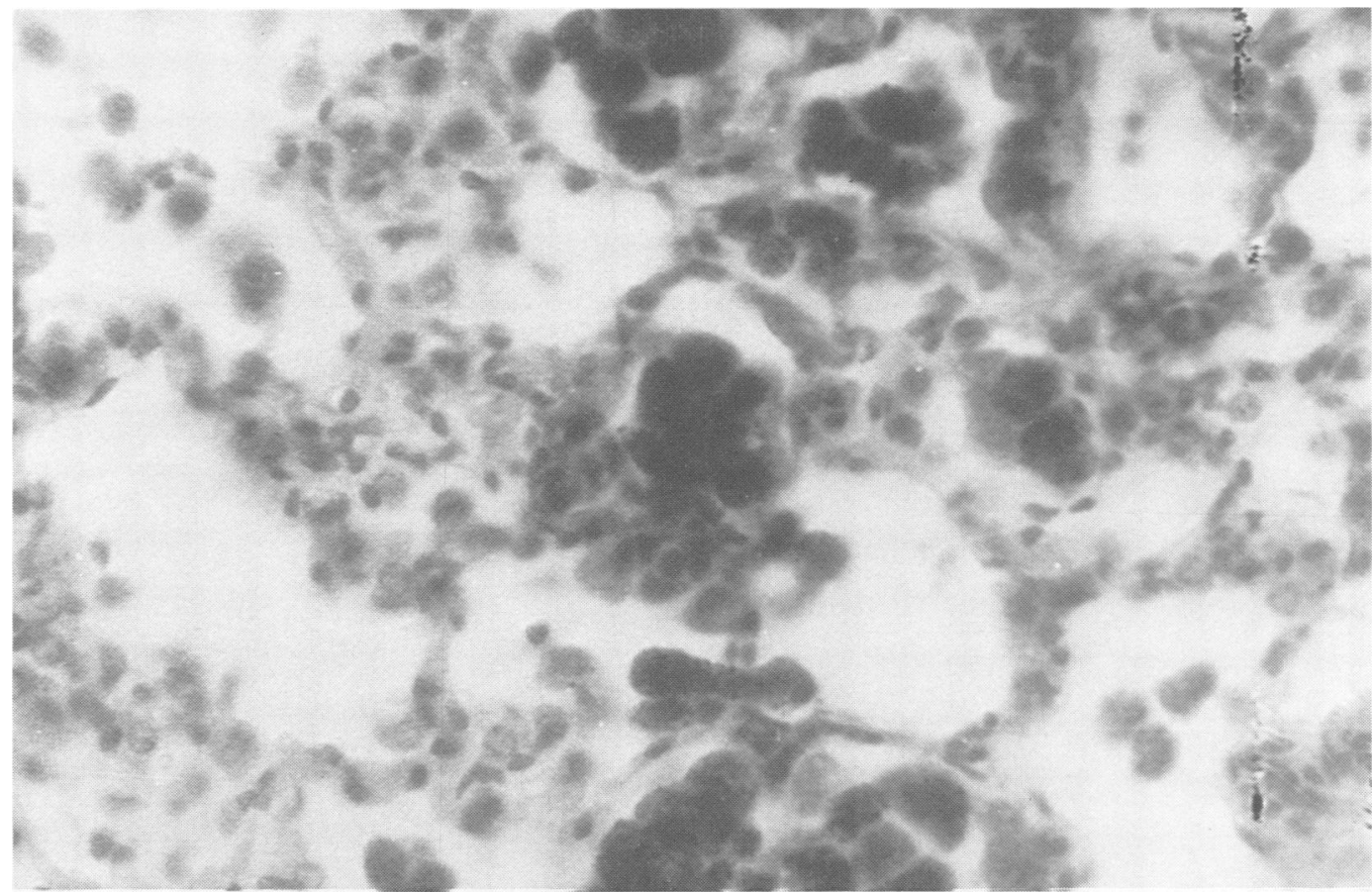

Fig 3 Section of lung of rat killed 30 days after intratracheal inoculation of quartz. (Rat had been similarly inoculated 60 days earlier with fly ash.) Fly ash particles are engulfed by alveolar macrophages. (Haematoxylin and eosin $\times 150$.)

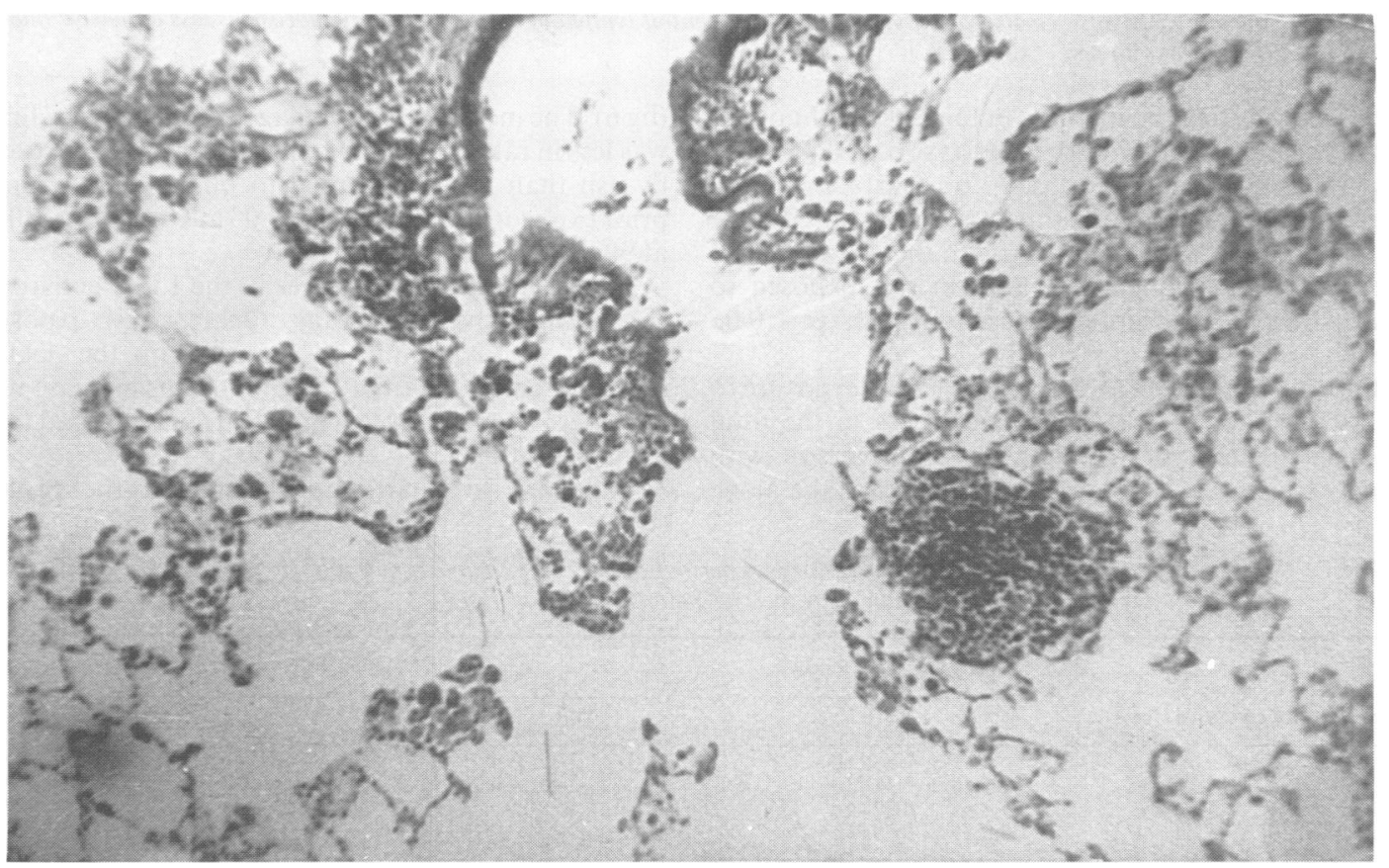

Fig 4 Same as fig 3 but 60 days after inoculation with quartz. Development of fly ash rich silicotic granulomas in proximal alveoli. (Haematoxylin and eosin $\times 150$.) 


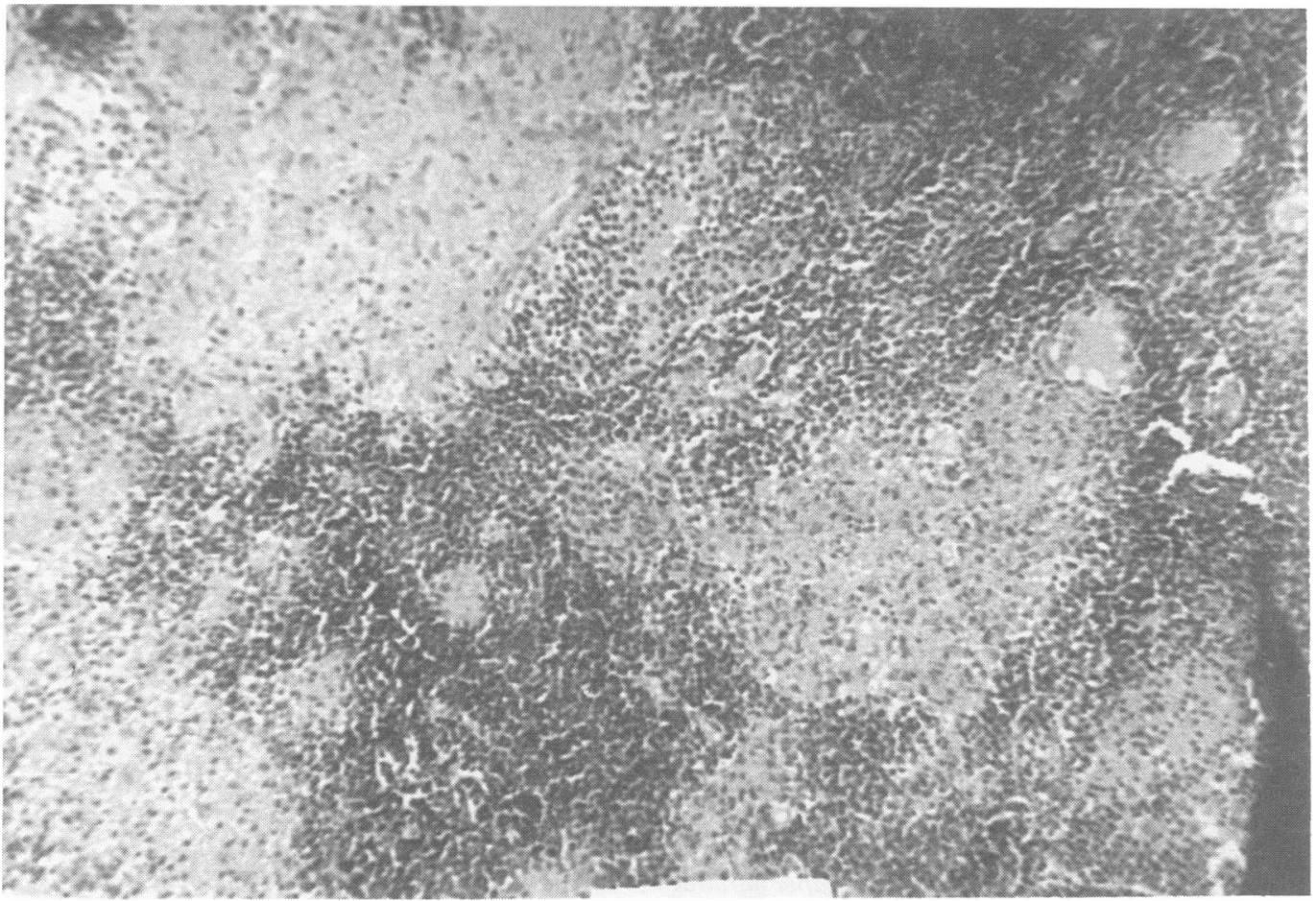

Fig 5 Section of mediastinal lymph node of rat killed 60 days after intratracheal inoculation of quartz. (Rat had been similarly inoculated 60 days earlier with fly ash.) Replacement of lymphoid tissue by silicotic fibrosis is less extensive than in fig 2. (Haematoxylin and eosin $\times 60$.)

exposed to fly ash the increase in the wet weight of the lungs was significantly less at 60 days $(p<0.05)$. The dry weight of lungs exposed to quartz increased irrespective of whether the rats were pre-exposed to fly ash or not (table 2). The increase in the dry weight of the lungs was significantly more in rats exposed to quartz dust without pre-exposure to fly ash $(\mathrm{p}<0.05$ at 60 days, $\mathrm{p}<0.01$ at 90 days).

Exposure to quartz after or without pre-exposure to fly ash resulted in a significant increase in the total collagen content of the lungs by comparison with lungs exposed to fly ash or physiological saline alone (fig 6). The increase in the collagen content of the lungs was less in rats exposed to quartz after pre-exposure to fly ash than in rats exposed to quartz dust without prior exposure to fly ash $(\mathrm{p}<0.05$ at 60 days, $\mathrm{p}<0.01$ at 90 days).

Figure 7 shows the changes in the LDH activity of the bronchoalveolar lavage. Quartz dust exposure resulted in a significant increase in the lactate dehydrogenase activity $(p<0.01)$. This increase was, however, significantly less in the rats pre-exposed to fly ash $(\mathrm{p}<0.01)$.

Exposure to quartz dust increased the protein

Table 1 Changes in wet weight of lungs ( $\mathrm{g}$ ) after varying periods of exposure to quartz (10 $\mathrm{mg}$ ) in rats pre-exposed to coal fly ash (12.5 mg) for 60 days. (Figures in parentheses represent number of animals used)

\begin{tabular}{llll}
\hline & \multicolumn{2}{l}{ Days after exposure } & \\
\cline { 2 - 4 } Experimental conditions $\dagger$ & 30 & 60 & 90 \\
\hline Fly ash + quartz & $4 \cdot 17 \pm 0 \cdot 58(3)^{*}$ & $2 \cdot 97 \pm 0 \cdot 21(3)^{* *}$ & $4 \cdot 19 \pm 1 \cdot 00(3)^{* *}$ \\
Fly ash & $1 \cdot 76 \pm 0 \cdot 11(3)$ & $2 \cdot 43 \pm 0 \cdot 29(3)$ & $1.53 \pm 0 \cdot 20(3)^{*}$ \\
Quartz & $3 \cdot 45 \pm 0 \cdot 52(4)$ & $4 \cdot 20 \pm 0.58(4)^{* *}$ & $4 \cdot 29 \pm 0.41(3)^{* *}$ \\
Control & $2 \cdot 45 \pm 0.79(4)$ & $2 \cdot 33 \pm 0.17(4)$ & $1.84 \pm 0.67(4)$ \\
\hline
\end{tabular}

†See text for full details.

${ }^{*} \mathrm{p}<0.05 ;{ }^{* *} \mathrm{p}<0.01 \pm$ SD. 
Table 2 Changes in dry weight of lung ( $\mathrm{g}$ ) after varying periods of exposure to quartz (10 $\mathrm{mg})$ in rats pre-exposed to coal fly ash ( $12.5 \mathrm{mg}$ ) for 60 days. (Figures in parentheses represent number of animals used)

\begin{tabular}{llll}
\hline & \multicolumn{2}{l}{ Days after exposure } & \\
\cline { 2 - 4 } Experimental conditions & 30 & 60 & 90 \\
\hline Fly ash + quartz & $0.49 \pm 0.13(3)^{*}$ & $0.42 \pm 0.05(3)^{*}$ & $0.44 \pm 0.02(3)^{* *}$ \\
Fly ash & $0.36 \pm 0.06(3)$ & $0.32 \pm 0.06(3)$ & $0.26 \pm 0.05(3)$ \\
Quartz & $0.47 \pm 0.07(4)^{*}$ & $0.53 \pm 0.06(4)^{* *}$ & $0.61 \pm 0.07(3)^{* *}$ \\
Control & $0.30 \pm 0.07(4)$ & $0.29 \pm 0.03(4)$ & $0.30 \pm 0.08(4)$ \\
\hline${ }^{*}<<0.05 * * * p<0.01+$ SD & & &
\end{tabular}

content of the bronchoalveolar lavage significantly $(p<0.01$ ) (fig 8). The bronchoalveolar lavage protein content of rats exposed to quartz dust after exposure to fly ash also increased significantly by comparison with the controls. The protein contents of the bronchoalveolar lavage at 60 days was significantly less in the rats exposed to fly ash quartz than in rats exposed to quartz alone $(p<0.01)$. Table 3 shows a significant increase in the cellular contents of the bronchoalveolar lavage in rats exposed to quartz dust or which was statistically significant at 60 days and 90 days after exposure. No increase in the bronchoalveolar lavage cellularity was noticed when the animals were preexposed to fly ash before exposure to quartz ( $\mathrm{p}<$ $0.01)$.

\section{Discussion}

The results of the present investigation show that the development of silicotic lesions is significantly retarded in rats pre-exposed to fly ash. The mechanism of this action is not known but seems to be related to the constituents of airborne pollutants from fossil fuel plants which are enriched in many metals and metalloids. ${ }^{14}$ In our earlier investigations it was

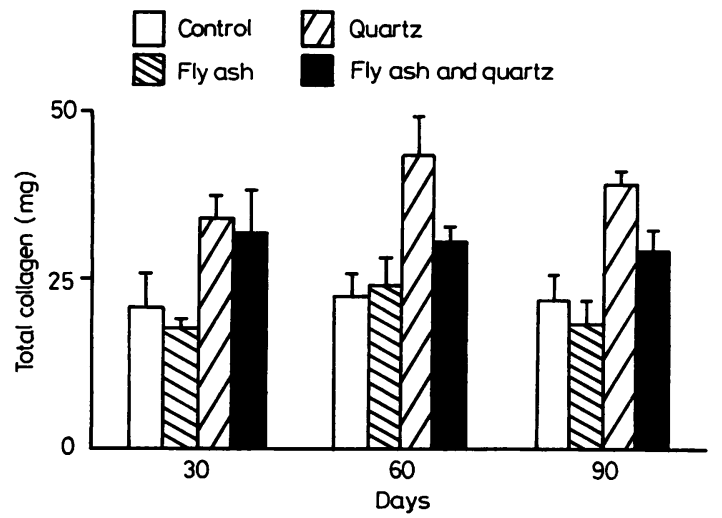

Fig 6 Changes in total collagen contents of lungs inculated with quartz and fly ash dusts intratracheally. observed that the fly ash remained in the lungs of rats for over 180 days.

This could be associated with concurrent retention in the lung parenchyma of metals associated with the fly ash. Some of these metals are highly soluble and would be expected to impair considerably the solubility of quartz. Experimental evidence in support of this presumption is that treatment of quartz with aluminium lactate or iron oxide modifies quartz surface and consequently reduces the biological activity of quartz. ${ }^{15}$

Exposure to some of the individual metals present in fly ash results in toxic manifestations in the lungs. ${ }^{16-21}$ By contrast, metal interactions have been reported to diminish the toxicity and the carcinogenic potential of inorganic and organic compounds. ${ }^{223}$ The results of the present investigation suggest that interaction of the different constituents of fly ash among themselves and with the constituents of other xenobiotics that impinge on the alveolar surface would greatly alter the

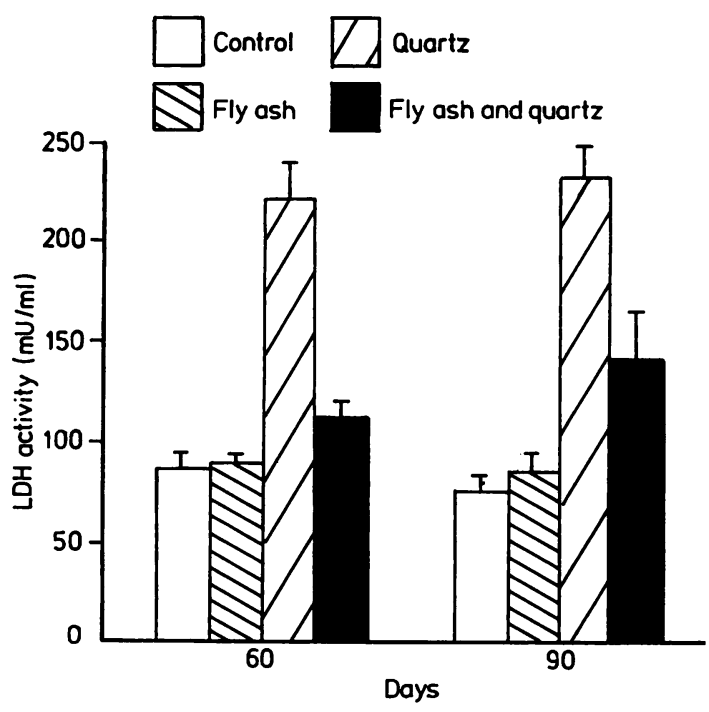

Fig 7 Lactate dehydrogenase activity of bronchoalveolar lavage of rats exposed to different dusts. 
Table 3 Changes in cell counts $\left(\times 10^{6}\right)$ in bronchoalveolar lavage after varying periods of exposure to quartz $(10 \mathrm{mg})$ in rats pre-exposed to coal fy ash (12.5 $\mathrm{mg}$ ) for 60 days. (Figures in parentheses represent number of animals used)

Days after exposure

\begin{tabular}{llll}
\cline { 2 - 4 } Experimental conditions & 30 & 60 & 90 \\
\hline Fly ash + quartz & $0.76 \pm 0.14(3)$ & $0.73 \pm 0 \cdot 14(3)$ & $0.88 \pm 0.08(3)$ \\
Fly ash & $0.83 \pm 0.15(4)$ & $0.83 \pm 0.07(4)$ & $0.78 \pm 0.14(4)$ \\
Quartz & $1.12 \pm 0.23(4)$ & $1.27 \pm 0.17(4)$ & $1.33 \pm 0.16(3)$ \\
Control & $0.95 \pm 0.31(4)$ & $0.85 \pm 0 \cdot 11(4)$ & $0.90 \pm 0.12(4)$ \\
\hline
\end{tabular}

sequence of the pathological events seen when either of the agents is administered alone.

Intratracheal inoculation of quartz dust increased the $\mathrm{LDH}$, protein, and cellular constituents in the bronchoalveolar lavage of the exposed rats. Similar results have also been obtained by others. ${ }^{24-26}$ The source of lactate dehydrogenase was not determined in the present investigation but could have been due to cellular damage or lysis of alveolar macrophages, since these cells release significant amounts of the enzyme in vitro. ${ }^{27}$ Diminished enzyme activity in the bronchoalveolar lavage of rats pre-exposed to fly ash would imply that fly ash either antagonised or reduced the cytotoxic potential of quartz before phagocytosis by macrophages in the extracellular milieu where some particles could be visualised by histopathological examination or within the cytoplasm of the macrophage after phagocytosis of the dust. Whether this type of interaction can take place within secondary lysosomes containing fly ash particles, or newly for-

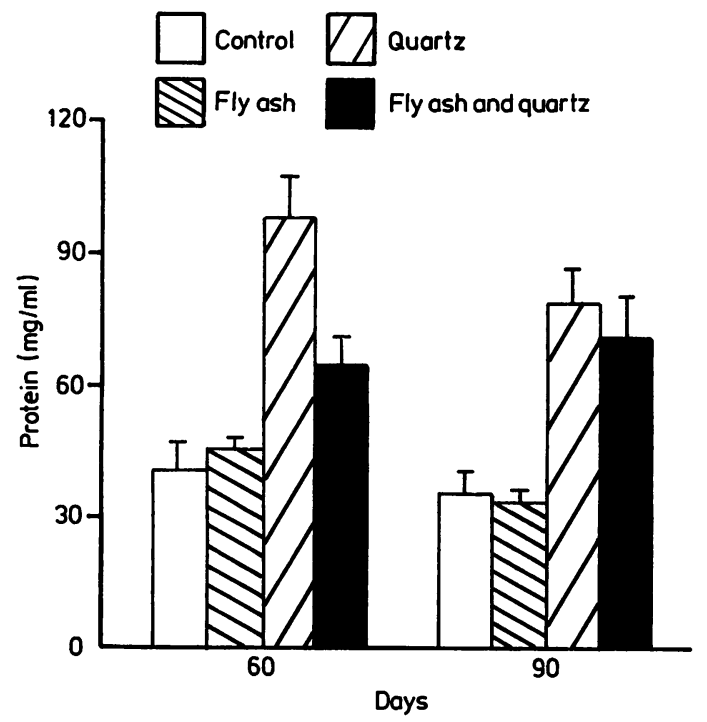

Fig 8 Protein content of bronchoalveolar lavage of rats exposed to different dusts. med secondary lysosomes, will require further studies at the ultramicroscopic level.

From the results of these studies it may, therefore, be concluded that small amounts of fly ash do not greatly alter pulmonary histopathology, that the dust remains in the lungs for long periods, and that in lungs pre-exposed to fly ash the fibrotic reaction after a subsequent exposure to proliferative dust such as quartz is retarded and less extensive.

\section{References}

1 Frederick ER. Particulate control in coal fired power plants. Indian Journal of Environmental Protection 1984;4:1-24.

2 Davison RL, Natusch DFS, Wallace JR. Trace elements in fly ash. Dependence of concentration on particle size. Environmental Science and Technology 1974;8:1107-13.

3 Chrisp CE, Fisher GL, Lammert JE. Mutagenicity of filtrates from respirable coal fly ash. Science 1978;199:73-5.

4 Natusch DFS. Potentially carcinogenic species emitted to the atmosphere by fossil-fueled power plants. Environ Health Perspect 1978;22:79-90.

5 Fischer GL, Chrisp CE, Raabe OG. Physical factors affecting the mutagenicity of fly ash from a coal fired power plant. Science 1979;204:879-81.

6 Kubitschek HE, Venta L. Mutagenicity of coal fly ash from electric power plant precipitators. Environ Mutagen 1979;1:79-82.

7 Schiff LJ, Byrne MM, Graham JA. Fly ash-induced changes in hamster tracheal epithelium in viva and in vitro. $J$ Toxicol Environ Health 1981;8:431-48.

8 Smith-Sonneborn J, Fischer GL, Palizzi RA, Herr C. Mutagenicity of coal fly ash. A new bioassay for mutagenic potential in a particle feeding ciliate. Environ Mutagen 1981;3:239-52.

9 Wei CI, Culbertson MR, Shifrine M, Rosenblatt LS, Chrisp CE. Comparative studies on in vivo carcinogenesis in rats and in vitro mutagenesis of mutagenic coal fly ash. J Toxicol Environ Health 1982;10:587-600.

10 Gordon H, Sweets HH Jr. A simple method for the silver impregnation of reticulum. Am J Pathol 1936;12:545-52.

11 Stegemann H. Microdetermination of hydroxyproline with chloromine T and $P$-dimethylamino benzaldehyde. Zeitschrift für Physikalische Chemie 1958;311:41-5.

12 Kornberg A. Lactic dehydrogenase of muscle. In: Colowick SP, Kaplan NO, eds. Methods of enzymology. Vol 1. New York: Academic Press Inc, 1955:441-3.

13 Lowry OH, Rosebrough NJ, Farr AL, Randall RJ. Protein measurement with the folin-phenol reagents. $J$ Biol Chem 1951;193:265-75.

14 Rhoads K, Sanders CL. Lung clearance, translocation and acute toxicity of arsenic, beryllium, cadmium, cobalt, lead, selenium, vanadium and ytterbium oxides, following deposition in rat lung. Environ Res 1985;36:359-78. 
15 Begin R, Geoffroy M, Masse S, Rola-Pleszczynski M, Desmaraus Y, Martel M. Lung tissue activity of American attapulgite. Am Rev Respir Dis 1985;131:A181.

16 Bonnel JA. Emphysema and proteinuria in men casting coppercadmium alloys. Br J Ind Med 1955;12:181-97.

17 Seaton A, Bishop CM. Acute mercury pneumonitis. Br J Ind Med 1978;35:258-65.

18 Stern RM, Pigott GH, Abraham JL. Fibrogenic potential of welding fumes. J Appl Toxicol 1983;3:18-30.

19 Johansson A, Curstedt T, Robertson B, Camner P. Lung morphology and phospholipids after experimental inhalation of soluble cadmium, copper and cobalt. Environ Res 1984:34:295-309.

20 Lundborg M, Camner P. Lysozyme levels in rabbit lung after inhalation of nickel, cadmium, cobalt and copper chlorides. Environ Res 1984;34:335-42.

21 Schiff LJ, Graham JA. Cytotoxic effect of vanadium and oil-fired fly ash on hamster tracheal epithelium. Environ Res 1984;
34:390-402.

22 Ridlington JW, Whanger PD. Interactions of selenium and antioxidant with mercury, cadmium and silver. Fundam Appl Toxicol 1981;1:368-75.

23 Fisher GL, McNeill KL, Democko CJ. Trace element interactions affecting pulmonary macrophage cytotoxicity. Environ Res 1986;39:164-71.

24 Morgan A, Moores SR, Holmes A, Evans JC, Evans NH, Black A. The effect of quartz administered by intratracheal instillation on the rat lung. I. The cellular response. Environ Res 1980;22:1-12.

25 Stankus RP, Salvaggio JE. Bronchopulmonary humoral and cellular enhancement in experimental silicosis. Journal of the Reticuloendothelial Society 1981;29:153-61.

26 Sjostrand M, Rylander R. Enzymes in lung lavage fluid after inhalation exposure to silica dust. Environ Res 1984;3:307-11.

27 Bansal SK, Kaw JL. Lactate dehydrogenase isoenzymes in macrophages and serum during the development of pulmonary silicosis in the rat. Toxicol Lett 1981;7:279-83.

\section{Destruction of manuscripts}

From I July 1985 articles submitted for publication will not be returned. Authors whose papers are rejected will be advised of the decision and the manuscripts will be kept under security for three months to deal with any inquiries and then destroyed. 